\title{
REVIEW
}

\section{Problem based learning}

D A Kilroy

Emerg Med J 2004;21:41 1-413. doi: 10.1136/emj.2003.012435

Problem based learning (PBL) has been the subject of considerable interest and debate in medical undergraduate and, increasingly, postgraduate education in recent years. Its supporters maintain that PBL enhances learning by providing a highly motivational environment for acquisition of knowledge, which is well received by those who take part in it. Critics argue that PBL is a time consuming exercise, often undertaken by people with a limited appreciation of its complexities, and the lack of evidence that PBL translates into better clinical competence brings into question the relevance of such intensive learning methods in everyday practice. This article outlines the background to PBL, explains its mechanics in action, and considers the potential disadvantages of its use as a clinical learning tool in the emergency department.

Correspondence to: Mr D Kilroy, Emergency Department, Trafford General Hospital, Manchester M41 5SL, UK; dakilroy@doctors.org.uk

Accepted for publication 30 October 2003
$\mathrm{P}$ roblem based learning (PBL) derives from a theory which suggests that for effective acquisition of knowledge, learners need to be stimulated to restructure information they already know within a realistic context, to gain new knowledge, and to then elaborate on the new information they have learned, for example by teaching it to peers or by discussing the material in a group setting. This theory is termed the information processing approach to learning and was initially described in $1977 .{ }^{1}$

PBL relies on the components of this theory. It differs from more "traditional" approaches to teaching in that the participants are encouraged to use self directed learning skills (placing emphasis on a person's ability to seek out and assimilate relevant information to tackle a problem at hand) to analyse a given clinical scenario, formulate and prioritise key learning objectives within that scenario, and then collect whatever additional information they think will be needed to address those objectives. Crucially, all this takes place within a group setting, so that each individual member of the group contributes to the learning process at every stage.

In relying heavily on the participants to make it effective, PBL embodies many of the key requisites of adult learning-particularly the sense of empowerment and "ownership" of the learning that adults are thought to value highly in their own education-but precisely how this can be measured in terms of "success" as a learning tool in a clinical setting has been hampered by the vague definitions of PBL in early studies. Barrows ${ }^{2}$ has devised a taxonomy to try to identify instances of "true" PBL learning and has concluded that the term best applies to teaching that achieves the following four important objectives in professional education:

- Structuring of knowledge for use in a clinical context

- Development of the student's clinical reasoning processes

- Development of self directed learning skills

- Increasing the student's motivation for further learning

It is important to be aware that PBL learning is quite separate from problem solving. The most "refined" form of PBL is termed closed loop PBL, where students complete the learning tasks set during their analysis of the original problem, but then go on at the end to identify areas for improvement in their own reasoning ability. This is considered a highly motivational method of learning.

PBL IN PRACTICE - A CLINICAL EXAMPLE Development of an effective PBL learning package should not be undertaken lightly: it is a very resource intensive process (participants will need reliable access to both the facilitator and the internet), which relies upon thorough knowledge of the principles of PBL as well as an enthusiastic group of colleagues who are keen to develop the skills needed to function as group learning facilitators.

The steps involved in PBL in practice can be summarised using a clinical example.

PBL session one: A\&E SHO teaching 1 July "A patient attends complaining of haemoptysis and chest pains. He is usually fit and well but smokes heavily. He is accompanied by his two teenage children. The family are Jehovah's Witnesses. How will you deal with the issues this patient's attendance raises?"

The open ended scenario is now used as a platform for the group to perform a series of tasks.

1 Clarify terms and decide the problems In our example there are several issues to address. Some terms may need clarification (do all group members understand the same thing by "haemoptysis"? Do all members understand the term Jehovah's Witness?) and the group must reach agreement about which aspects of this case need attention within the context of emergency care.

2 Analyse the problems

This consists in large part of utilisation of students' prior knowledge, to try and formulate hypotheses to explain the processes that have contributed to this clinical presentation. It 
commonly becomes a "brainstorming" session. The aim is to encourage all group participants to develop some insight into the underlying organic and social issues that might be at play.

\section{Identify study priorities for the scenario} Usually, there will be insufficient time to address all the issues raised. This important step entails prioritisation of those aspects of the scenario needing most attention-just as in real life.

\section{Formulate learning objectives for the problems} This step carries over from step 3. It is usual to draw up a list at this point on which all the group can agree: the objectives upon which the learners will concentrate are set out. It may be helpful to delegate tasks at this stage. The group must also identify what resources will be needed to help answer the questions they have set. In our example, the group might come up with:

- What is the immediate management of chest pain? (Bill to do-look at handbook and internet search ?Medline practice!)

- What is the most appropriate investigation pathway for haemoptysis? (Alan to do-look in textbooks, any evidence for best tests?)

- How does being a Jehovah's Witness affect care in A\&E? (Helen and Mike-speak to religion liaison people and look on web)

Note that the group have not answered all the possible questions that this scenario raises, just the ones which they felt were most appropriate.

\section{Individual study}

This step requires a high degree of motivation if the PBL is to be effective. There are real constraints in finding the time and energy to search out and assimilate the information needed. At this stage, the facilitator must be available when needed to assist with finding the information or to deal with problems in completing the tasks within the given time.

\section{PBL session two: 8 July (step 6)}

At this session, the group meet and share their findings. It is important that each participant fully contributes: they may make presentations to other group members, lead a discussion, or produce a handout. New questions may have arisen, and the group may decide to "step back" and re-analyse their priorities in this scenario.

\section{Identify areas for improvement}

In this phase, group members look at how they approached the earlier steps and consider if they have developed new skills as a result of their studies. This reflective activity can be very revealing and is a powerful motivator to further useful clinical learning.

\section{WHAT MAKES A GOOD PBL PROBLEM?}

PBL only has the potential to be effective if care is taken to set problems that work well with this learning style. ${ }^{3}$ The following points must be considered:

- There should be a neutral description of a realistic and fairly common clinical scenario that needs explanation in terms of underlying principles or processes;

- There must be the scope for problem solving activity: our earlier example would be useless for PBL if it simple stated, "give an account of the causes and treatment of haemoptysis";
- The problems must be formulated in a clear and concrete manner;

- There should be a degree of complexity to the scenario that is appropriate to the participants: too simplistic a scenario will not motivate anyone. One of the strengths of PBL is that "simpler" tasks can be allocated to those whose knowledge base or learning skills are comparatively weak, and "complex" tasks allocated to stronger group members, without anyone necessarily being disempowered: within an adult learning environment, it is crucial to acknowledge all contributions to the learning, and responsible participants work within this framework quite easily;

- An element of medical urgency to the problem helps promote high quality participation for learners whose clinical work role is in the emergency department;

- Problems raising issues that are often poorly handled by healthcare staff are particularly powerful learning tools.

\section{DOES PBL REQUIRE A TEACHER?}

So far, there has been little mention of the "teacher" in problem based learning. PBL differs radically from traditional teaching styles in that it centres on "problem first" learning, rather than the more usual "subject first" way using scenarios to illustrate previously taught material. The leader of a PBL programme acts as a facilitator rather than a teacher, using their expertise not primarily to transmit facts, but to provide encouragement and guidance as the participants tackle the problems they have identified. The skill of PBL facilitation is that of knowing when to provide assistance to the group, be it suggesting useful resources they might like to consider or interjecting with thought provoking comments to guide the breadth and depth of learning, without necessarily imparting facts. ${ }^{4}$ There has been debate as to whether the facilitator needs to be an "expert in the field" regarding the subject matter being tackled, but the consensus view is that expertise in group dynamics together with supportive enthusiasm is more valuable than deep subject knowledge. The potential for "non-medical" facilitators to help with teaching in the emergency department is therefore significant. This has been a difficult idea for some "medical" teachers to grasp. ${ }^{5}$

\section{DOES PBL WORK?}

Much of the early work on PBL described its use in the undergraduate setting, particularly the preclinical years. There remains little information about its use in postgraduate education. ${ }^{6}$ The issue of PBL's effectiveness is a vexed one because of difficulties surrounding terminology-several literature reviews have discovered that many papers seemingly reporting "PBL" initiatives actually describe activities such as journal clubs or self directed study groups without several of the components of PBL proper. ${ }^{7}$ There are further difficulties, as with much educational research, in determining exactly what we mean by "does it work?" If we are asking whether PBL leads to greater participant enjoyment and enthusiasm for learning than more "traditional" methods of medical education, then there is plenty of evidence to support this: PBL learners feel they are being treated as mature professionals who are developing effective and clinically relevant study skills as well as useful skills in problem solving that are vital in their working life. They also value the interpersonal skills that PBL encourages and that are also key to effective clinical practice. ${ }^{8}$ There is practically no evidence, however, that $\mathrm{PBL}$ participants demonstrate improved clinical competence or have more effective clinical consultations, although it might be argued that in becoming more confident and self aware as professional learners they will presumably become more efficient and enthusiastic in the 


\begin{tabular}{|ll|}
\hline \multicolumn{2}{|l|}{ Table 1 Advantages and disadvantages } \\
\hline Advantages & Disadvantages \\
\hline Helps develop key learning skills & Time consuming to set up at start \\
Helps develop key interpersonal skills: & Time consuming to facilitate \\
communication & Must be prepared to "step back" \\
prioritisation of time/resources & from "traditional' teaching role \\
identification of key problems & Demands easy access to internet and \\
teamworking and task sharing & good quality medical library \\
Potential to increase learner confidence & Not suited to all subject areas \\
\hline
\end{tabular}

workplace. ${ }^{9}$ These remain broad assumptions, though, and the relative newness of postgraduate PBL accounts for the lack of clarity in this area.

\section{PBL IN THE EMERGENCY DEPARTMENT}

Teaching for junior staff in the emergency department has traditionally taken the form of half day sessions where a series of lectures or skill stations are held. There is no generic national curriculum to determine what subjects should be learned during these sessions at senior house officer level, and there is good evidence that this traditional teaching format is particularly unsatisfying and unproductive for adult learners. Emergency care lends itself to application of PBL principles for the education of junior staff: it develops skills that are highly appropriate for the multidisciplinary team approach of the emergency department and equips participants with vital lifelong skills in self directed study and resourcefulness. It is important, however, to be aware of the limitations of PBL. It requires a good deal of planning and ongoing facilitation. Participants must be clearly aware of what is expected of them. Overseeing a PBL programme can be very tiring and involves group management skills that can run counter to the natural desire to "help out" by supplying the answers. Moreover there are some topics for which PBL will not be an appropriate educational tool. And, lastly, enthusiasm for PBL should not hide the fact that, although it is popular and well received by learners, there is unlikely to be any measurable way of translating this into improved subsequent quality of care. It stands to reason, though, that by providing a more stimulating learning environment for junior staff, PBL can help make them more satisfied and more confident in their clinical role (table 1).

\section{REFERENCES}

1 Anderson RC. The notion of schemata and the educational enterprise: general discussion of the conference. In: Anderson RC, Spiro RJ, Montague WE, eds. Schooling and the acquisition of knowledge. Hillsdale, NJ: Erlbaum, 1977.

2 Barrows HS. A taxonomy of problem- based learning methods. Med Educ 1989;20:481-6.

3 Neame RLB. How to construct a problem-based course. Medical Teacher 1981;3:94-9.

4 Maudsley G. Roles and responsibilities of the problem-based learning tutor in the undergraduate medical curriculum. BMJ 1999;318:657-61.

5 Vernon DTA. Attitudes and opinions of faculty tutors about problem-based learning. Acad Med 1995:70:216-23.

6 Smits PBA, Verbeek JHAM, de Buisonje CD. Problem-based learning in continuing medical education: a review of controlled evaluation studies. BMJ 2002;324:153-6.

7 Foley RP, Polson AL, Vance JM. Review of the literature on PBL in the clinical setting. Teaching and Learning in Medicine 1997:9:4-9.

8 Colliver JA. Effectiveness of problem-based learning curricula: research and theory. Acad Med 2000;75:259-66.

9 Albanese M. Problem-based learning: why curricula are likely to show little effect on knowledge and clinical skills. Med Educ 2000;34:729-38. 